\title{
Corrigendum: Acceleration of Debris Flow Due to Granular Effect
}

\author{
Taiqiang Yang ${ }^{1,2}$, Yong $\mathrm{Li}^{1 *}$, Xiaojun Guo ${ }^{1,3 *}$, Jun Zhang ${ }^{1,2}$, Yu Jiang ${ }^{4}$, Xuemei Liu ${ }^{1,2,5}$ and \\ Jingjing Liu ${ }^{1}$ \\ ${ }^{1}$ Key Laboratory of Mountain Hazards and Earth Surface Processes/Institute of Mountain Hazards and Environment, Chinese \\ Academy of Sciences, Chengdu, China, ${ }^{2}$ University of Chinese Academy of Sciences, Beijing, China, ${ }^{3}$ Center for Excellence in \\ Tibetan Plateau Earth Sciences, Chinese Academy of Sciences, Beijing, China, ${ }^{4}$ School of Engineering and Technology, Baoshan \\ University, Baoshan, China, ${ }^{5}$ Sichuan Earthquake Administration, Chengdu, China
}

Keywords: debris flow, excess pore pressure, stress distribution, mobility, self-acceleration effect

\section{OPEN ACCESS}

Approved by:

Frontiers Editorial Office, Frontiers Media SA, Switzerland

${ }^{*}$ Correspondence: Yong $\mathrm{Li}$

ylie@imde.ac.cn

Xiaojun Guo

aaronguo@imde.ac.cn

Specialty section:

This article was submitted to Earth and Planetary Materials,

a section of the journal

Frontiers in Earth Science

Received: 14 October 2021

Accepted: 21 October 2021

Published: 08 November 2021

Citation:

Yang T, Li Y, Guo X, Zhang J, Jiang Y, Liu $X$ and Liu J (2021) Corrigendum: Acceleration of Debris Flow Due to

Granular Effect.

Front. Earth Sci. 9:794994.

doi: 10.3389/feart.2021.794994

\section{A Corrigendum on}

Acceleration of Debris Flow Due to Granular Effect

by Yang, T., Li, Y., Guo, X., Zhang, J., Jiang, Y., Liu, X., and Liu, J. (2021). Front. Earth Sci. 9:660605. doi: $10.3389 /$ feart.2021.660605

In the published article, there were errors in affiliations 1 and 2. Instead of "1 Key Laboratory of Mountain Hazards, Surface Process/Institute of Mountain Hazards and Environment, Chinese Academy of Sciences, Chengdu, China" and "2 Institute of Mountain Hazards and Environment, University of Chinese Academy of Sciences, Beijing, China", it should be "1 Key Laboratory of Mountain Hazards and Earth Surface Processes/Institute of Mountain Hazards and Environment, Chinese Academy of Sciences, Chengdu, China” and "2University of Chinese Academy of Sciences, Beijing, China".

The authors apologize for these errors and state that they do not change the scientific conclusions of the article in any way. The original article has been updated.

Publisher's Note: All claims expressed in this article are solely those of the authors and do not necessarily represent those of their affiliated organizations, or those of the publisher, the editors and the reviewers. Any product that may be evaluated in this article, or claim that may be made by its manufacturer, is not guaranteed or endorsed by the publisher.

Copyright (c) 2021 Yang, Li, Guo, Zhang, Jiang, Liu and Liu. This is an open-access article distributed under the terms of the Creative Commons Attribution License (CC BY). The use, distribution or reproduction in other forums is permitted, provided the original author(s) and the copyright owner(s) are credited and that the original publication in this journal is cited, in accordance with accepted academic practice. No use, distribution or reproduction is permitted which does not comply with these terms. 